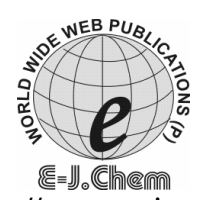

\title{
Development and Validation of a HPLC Method for Determination of Anastrozole in Tablet Dosage Form
}

\author{
D.SATHIS KUMAR*, A.HARANI, D.SRIDHAR, \\ DAVID BANJI, KNV RAO, GURUVIAH ${ }^{\S}$ and YOGESWARAN \\ Department of Pharmaceutical Analysis \\ Nalanda College of Pharmacy, Nalgonda-508001, India \\ ${ }^{\S}$ Matrix Lab, Hyderabad, India \\ satmpdina@yahoo.co.in
}

Received 10 September 2010; Accepted 6 November 2010

\begin{abstract}
A simple, economic, accurate reverse phase isocratic HPLC method was developed for the quantitation of anastrozole in tablet dosage form. The quantification was carried out using Gracesmart RP18, $5 \mu$ (100 mm x $4.6 \mathrm{~mm})$ with UV detected at $215 \mathrm{~nm}$. The elution was achieved isocratically with a mobile phase comprising a mixture of buffer $(\mathrm{pH}$ 6.0) and acetonitrile $(1: 1$, $\mathrm{v} / \mathrm{v})$. The flow rate was $1.0 \mathrm{~mL} / \mathrm{min}$ The procedure was validated as per $\mathrm{ICH}$ rules for accuracy, precision, detection limit, linearity, reproducibility and quantitation limit. The linearity concentration range was $10-20 \mathrm{mcg} / \mathrm{mL}$ with the correlation coefficient of 0.9935 . The percentage recovery for Anastrozole was found to be $97.31 \pm 2.2 \%$. Limit of detection and limit of quantitation values were found to be $0.351 \mathrm{mcg} / \mathrm{mL}$ and $1.053 \mathrm{mcg} / \mathrm{mL}$. The method has been successfully used to analyze commercial solid dosage containing $1 \mathrm{mg}$ of anastrozole with good recoveries and proved to be robust.
\end{abstract}

Keywords: Anastrozole, Tablets, HPLC, Validation.

\section{Introduction}

Anastrozole is chemically known as (1,3-benzenediacetonitrile, $\alpha, \alpha, \alpha^{\prime}, \alpha^{\prime}$-tetramethyl-5- $(1 H$ 1,2,4-triazol-yl-methyl) which is a potent aromatase inhibitor. It is a white crystalline solid, odorless and is freely soluble in methanol, acetone, ethanol and tetrahydrofuran, and very soluble in acetonitrile ${ }^{1,2}$ having melting point $81-82{ }^{0} \mathrm{C}$. Anastrozole is indicated for the treatment of advanced breast cancer in postmenopausal women with disease progression following tamoxifen therapy and even in patients with ER negative disease ${ }^{3}$. Anastrozole is not official in IP, USP and BP. Several methods have been used for the determination of anastrozole substance and pharmaceutical preparation. Saravanan et al. ${ }^{4}$ carried out the gradient RPLC method where a Hichrom RPB 18(250x4.6mm, $5 \mu)$ column using water in the mixture of acetonitrile and methanol (1:1) as mobile phase. The wavelength was $215 \mathrm{~nm}$. 
Mendes et $a l .{ }^{5}$ reported a novel method to measure anastrozole by HPLC-MS-MS using acetonitrile: methanol: water: acetone (60:20:15:5) as mobile phase. The focus of present study is to develop and validate a rapid, stable and economic, high performance liquid chromatographic method for the quality control of Anastrozole in Tablet dosage form.

\section{Experimental}

A reference standard sample of anastrozole was obtained from NATCO Pharma Limited and commercial dosage forms containing the studied drug were obtained from local market. The HPLC grade solvents used were of E-merk (India) Ltd., Mumbai. HPLC grade water was prepared using Millipore purification system. A isocratic HPLC system (Analyical Technologies Ltd) consisting of a model ALC 2010 high pressure pump and a model ASPD 2600 vaiable wavelength detector (UV-Vis) was used. Manual injections were made using a Rheodyne Injectable valve ( $20 \mu \mathrm{L}$ loop). The detector wavelength was set at $215 \mathrm{~nm}$. The chromatographic separations were performed at ambient temperature on a Gracesmart RP18, $5 \mu(100 \mathrm{~mm} \times 4.6 \mathrm{~mm})$. The mobile phase was a mixture of acetonitrile/Phosphate buffer $\mathrm{pH}$ $6.0 \pm 0.05(1: 1, \mathrm{v} / \mathrm{v})$, filtered and degassed prior to use and flowing at the rate of $1.0 \mathrm{~mL} / \mathrm{min}$ and run time is 15 minutes. Buffer was prepared by dissolving $1.36 \mathrm{~g}$ of potassium dihydrogen orthophosphate in $500 \mathrm{~mL}$ of water, adjusted the $\mathrm{pH}$ to $6.0 \pm 0.05$ with triethylamine and filtered through $0.45 \mu$ filter porosity membrane filter. The data were collected and analyzed with crystal software in a computer system. Mobile phase used as diluents.

\section{Preparations}

About $10 \mathrm{mg}$ of standard anastrozole was accurately weighed and dissolved in $50 \mathrm{~mL}$ of diluent in the volumetric flask to get a concentration of $200 \mu \mathrm{g} / \mathrm{mL}$. From this stock solution, suitable dilutions were made to get the concentrations of $10-30 \mu \mathrm{g} / \mathrm{mL}$ and filtered through $0.45 \mu$ filter porosity membrane filter before use. $20 \mu \mathrm{L}$ of each solution was injected into the column. All measurements were repeated five times for each concentration. The calibration curve was constructed by plotting the peak area ratios of analyte versus the respective drug concentration. Fifteen tablets were accurately weighed and powdered. An accurately weighed portion of the powder equivalent to $10 \mathrm{mg}$ of anastrozole was extracted in $25 \mathrm{~mL}$ of diluent in to a $50 \mathrm{~mL}$ volumetric flask by means of sonication for $25 \mathrm{~min}$ with intermittent vigorous shaking. The volume was made up to the mark with diluent and was centrifuged at $10000 \mathrm{RPM}$ for 10 minutes and $5 \mathrm{~mL}$ of supernatant solution was again diluted to $50 \mathrm{~mL}$ with diluents and mixed and filtered through $0.45 \mu$ filter porosity membrane filter before use.

\section{Validation}

The described method has been validated for the assay of Anastrozole using following parameters ${ }^{6,7,8}$. Precision was studied to find out intra and inter day variations in the test methods of Anastrozole on the same day and on another day at 3 different concentration levels, 18, 20 and $22 \mu \mathrm{g} / \mathrm{mL}$. three times. Intra day precision and Inter day precision were done on the same day and the differenct day respectively and the \%RSD was calculated for each. Data are present in Table 1 . The accuracy of the method was shown by analyzing model mixtures which were obtained by adding known amount of anastrozole to pharmaceutical preparation. The model mixtures contained 80(I), 100(II) and 120\% (III) of anastrozole compared to the labeled drug amount. For each model mixture three determinations of anastrozole were made. The retention time was calculated as 0,8 and $24 \mathrm{~h}$ for the concentrations of $20 \mu \mathrm{g} / \mathrm{mL}$ at various conditions like acid stress, base stress and peroxide stress. This was done by small deliberate changes in the chromatographic conditions at 3 different levels $-1,0,+1$ and retention time of the drug was noted. The factors selected were flow rate, $\mathrm{pH}$ and percentage of acetonitrile in the mobile phase. 
Stability of the method was determined by assay of the drug formulation at the interval of $8 \mathrm{~h}$ for a period of $48 \mathrm{~h}$ and compared with freshly prepared solutions. Still we are proceeding with stability studies. Limit of detection and limit of quantitation were calculated by the method which was a common approach which is to compare measured signals from samples with known low concentrations of analyte with those of blank samples; the minimum concentration at which the analyte can be reliably detected is established.

Table 1. Data for precision

\begin{tabular}{|c|c|c|c|c|c|c|}
\hline & \multicolumn{3}{|c|}{$\begin{array}{l}\text { Intra day Precision } \\
\text { Conc., } \mu \mathrm{g} / \mathrm{mL}\end{array}$} & \multicolumn{3}{|c|}{$\begin{array}{l}\text { Inter day Precision } \\
\text { Conc., } \mu \mathrm{g} / \mathrm{mL}\end{array}$} \\
\hline & 18 & 20 & 22 & 18 & 20 & 22 \\
\hline \multirow{3}{*}{ Peak area } & 414.229 & 437.426 & 557.01 & 414.229 & 436.256 & 554.25 \\
\hline & 409.26 & 435.26 & 550.26 & 420.36 & 442.23 & 572.12 \\
\hline & 405.253 & 430.10 & 556.21 & 407.256 & 450.12 & 562.22 \\
\hline Injection Volume, $\mu \mathrm{L}$ & 20 & 20 & 20 & 20 & 20 & 20 \\
\hline Mean & 409.58 & 434.26 & 554.49 & 413.94 & 442.86 & 562.86 \\
\hline Std. deviation & 4.49 & 3.76 & 3.68 & 6.55 & 6.95 & 8.95 \\
\hline$\%$ RSD & 1.09 & 0.86 & 0.66 & 1.58 & 1.57 & 1.59 \\
\hline
\end{tabular}

\section{Results and Discussion}

A reverse-phase isocratic procedure is proposed as a suitable method for the analysis of anastrozole in tablets. A mixture of Phosphate buffer $\mathrm{pH}$ 6.00/acetonitrile $(1: 1, \mathrm{v} / \mathrm{v})$ at a flow rate of $1.0 \mathrm{~mL} / \mathrm{min}$ was found to be an appropriate mobile phase allowing adequate and rapid separation of analyte. Retention time was found to be $5.31 \mathrm{~min}$. The percentage of purity of anastrozole in tablet dosage form is $97.31 \pm 2.2$. As shown in the Figure 1 the substances were eluted forming well shaped, symmetrical single peaks, well removed from the solvent front. For quantitative application a linear calibration curve was obtained over the concentration range $10-30 \mu \mathrm{g} / \mathrm{mL}$. The parameters of the calibration graph were $\mathrm{y}=29.65(\mathrm{x})-126.63$; where $\mathrm{x}$ is concentration and $\mathrm{y}$ is peak area; correlation coefficient $r=0.9935$. Percentage curve fitting was found to be $99.35 \%$. Calibration curve was present in Figure 2. The retention time of the curve at various conditions were found as. Acid stress $(0.1 \mathrm{M} \mathrm{HCl}): 5.647,5.310$ and 5.303, Base stress (0.1M NaOH): 5.297, 5.277 and 5.267, Peroxide stress $\left(5 \% \mathrm{H}_{2} \mathrm{O}_{2}\right): 5.334,5.413$ and 5.275 . The results of specificity indicate that retention time was little affected by small variations in these parameters. The results of robustness indicate that the selected factors were little affected by small variations in these parameters. There was almost no appreciable change in absorbance up to $48 \mathrm{~h}$ at room temperatures.

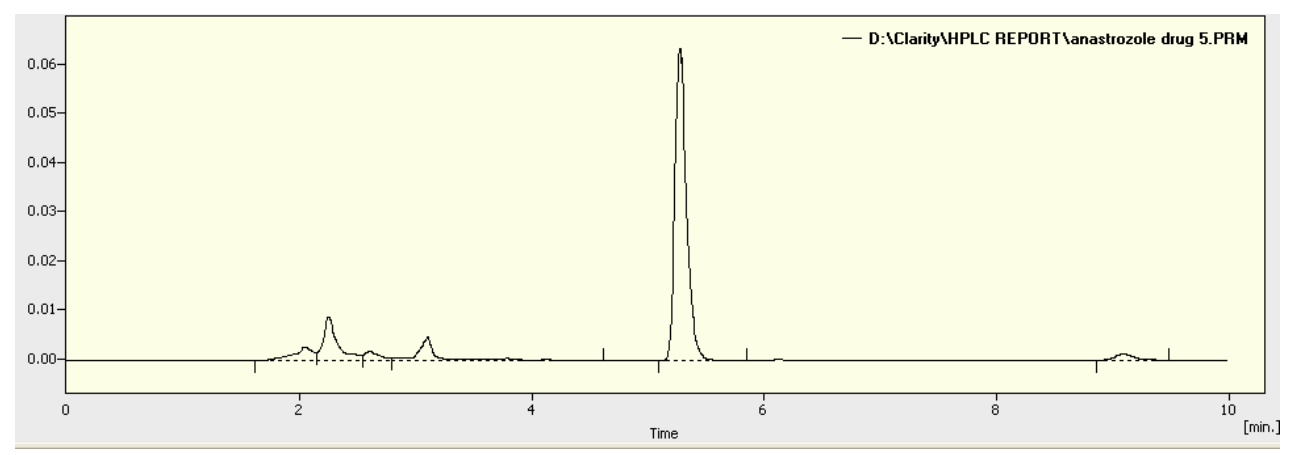

Figure 1. Chromatogram of anastrozole standard 


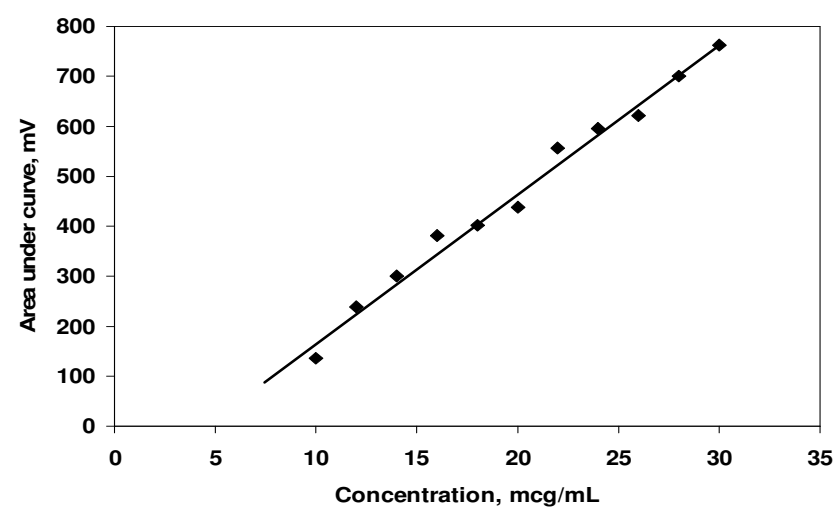

Figure 2. Calibration curve for linearity data

Percentage purity of the assays was found to be within 94.21 to $98.3 \%$. Thus the proposed method was found to provide high degree of stability. The selectivity of this method is shown by the fact that the excipents from tablets did not interfere in determining the substances analysed. The precision of the HPLC system was determined using the \%RSD of the peak areas for six injections of the standard solution. The \%RSD was less than 2 . In order to verify the accuracy of the described method, recovery studies were carried out by analyzing model mixtures of anastrozole. The recovery of anastrozole was evaluated from 80 to $120 \%$ of the labeled tablet. The percentage recoveries were found to be $97.67 \pm 2.1 \%, 96.78 \pm 1.3 \%$ and $97.33 \pm 0.9 \%$ respectively. Limit of detection and limit of quantitation were found to be $0.351 \mathrm{mcg} / \mathrm{mL}$ and $1.053 \mathrm{mcg} / \mathrm{mL}$ respectively.

\section{Conclusion}

The presented method is precise, sensitive and accurate. The advantages of proposed method are its short analysis time and a simple procedure for sample preparation. The satisfying recoveries and low coefficient of variation confirmed the suitability of proposed method for the routine analysis of anastrozole in pharmaceuticals.

\section{Acknowledgment}

The authors are thanks to the Management, Nalanda College of Pharmacy, Nalgonda for their support for the completion of this work.

\section{References}

1. Budavari S, O'Neil M, Ann Smith, Heckelman P and Obenchain J, Anastrozole, The Merck Index An Encyclopedia of Chemicals, Drugs, and Biologicals, $12^{\text {th }}$ Edition, Merck Research Laboratories Division of Merck \& Co., Inc., Whitehouse Station, NJ, 1996, 668.

2. Wellington K and Faulds D M, Drugs, 2002, 62(17), 2483-2490.

3. Plourde P V, Breast Cancer Res Treat., 1994, 30, 103-111.

4. Saravanan G, Suryanarayana M V, Jadhav M J, Ravikumar M, Someswararao N and Acharyulu P V R, Chromatographia, 2007, 66, 435-438.

5. Gustova D Mendes, Hamamoto D, Ilha J, Pereira A D S and Nucci G D, $J$ Chromatogr B, 2007, 850, 553-559.

6. Sethi P D, HPLC quantitative analysis of pharmaceutical formulation, CBS publication, New Delhi, 1996, 11-160.

7. Alfonso R. Gennaro Remington, The Science and Practice of Pharmacy, $20^{\text {th }}$ Edition. Baltimore, MD, Lippincott Williams \& Wilkins, Philadelphia, 2000, Vol 1, pp 603-620.

8. International conference on Harmonization, draft guideline on validation procedure, definition and terminology federal register, 1995, 60, 11260 . 


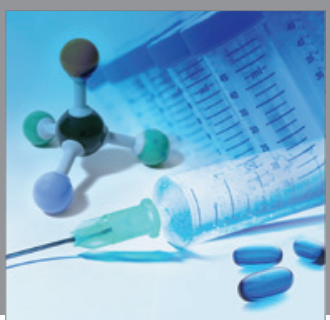

International Journal of

Medicinal Chemistry

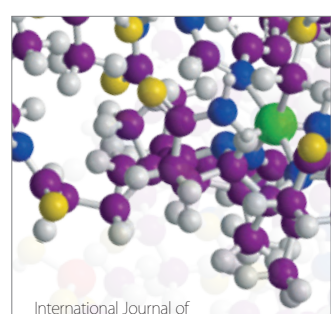

Carbohydrate Chemistry

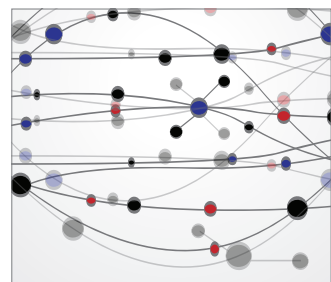

The Scientific World Journal
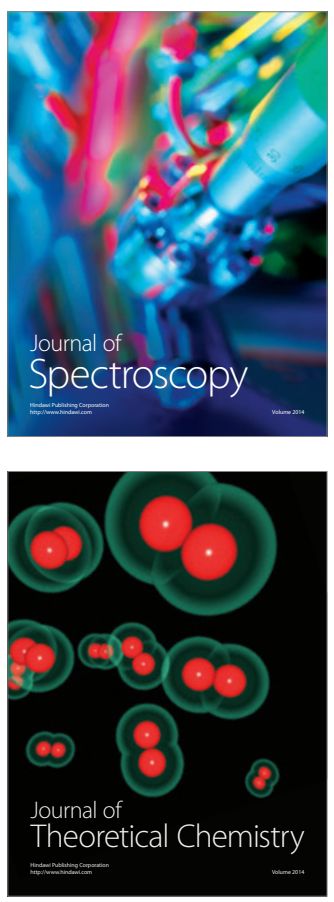
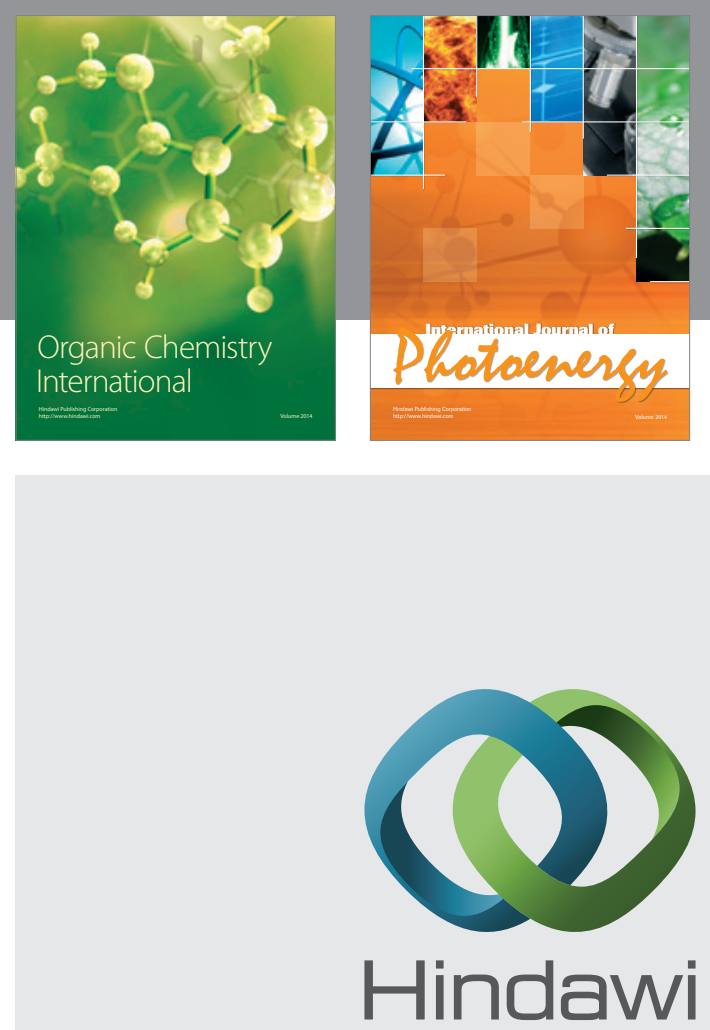

Submit your manuscripts at

http://www.hindawi.com
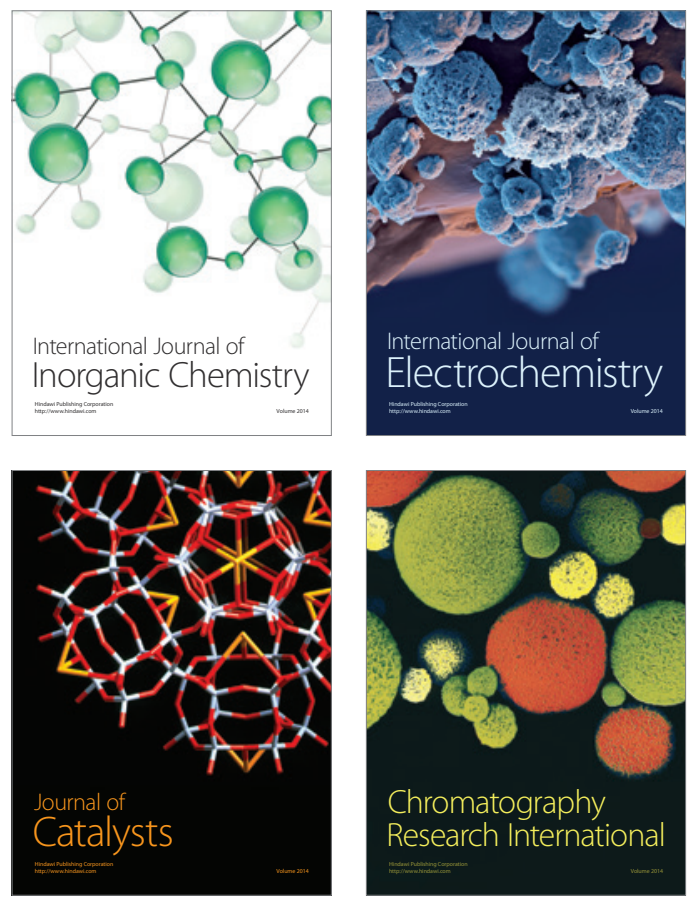
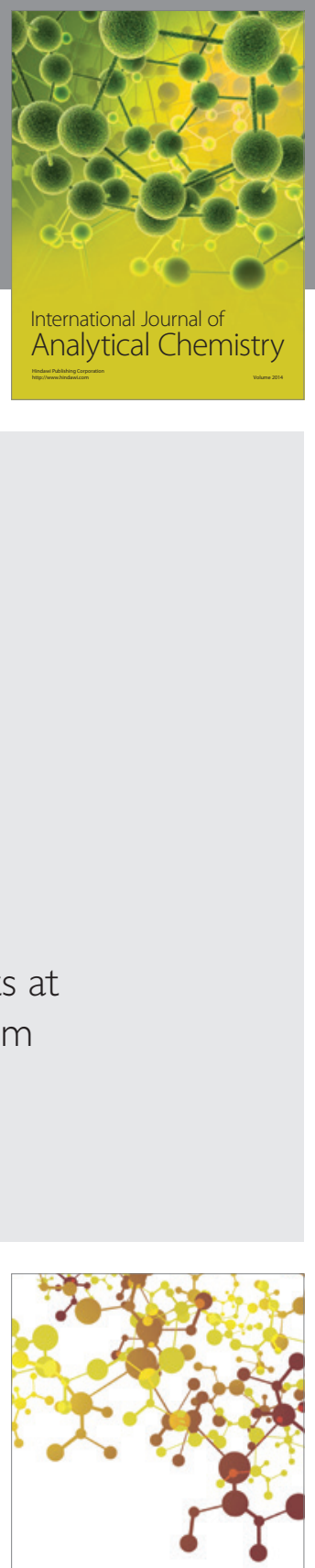

Journal of

Applied Chemistry
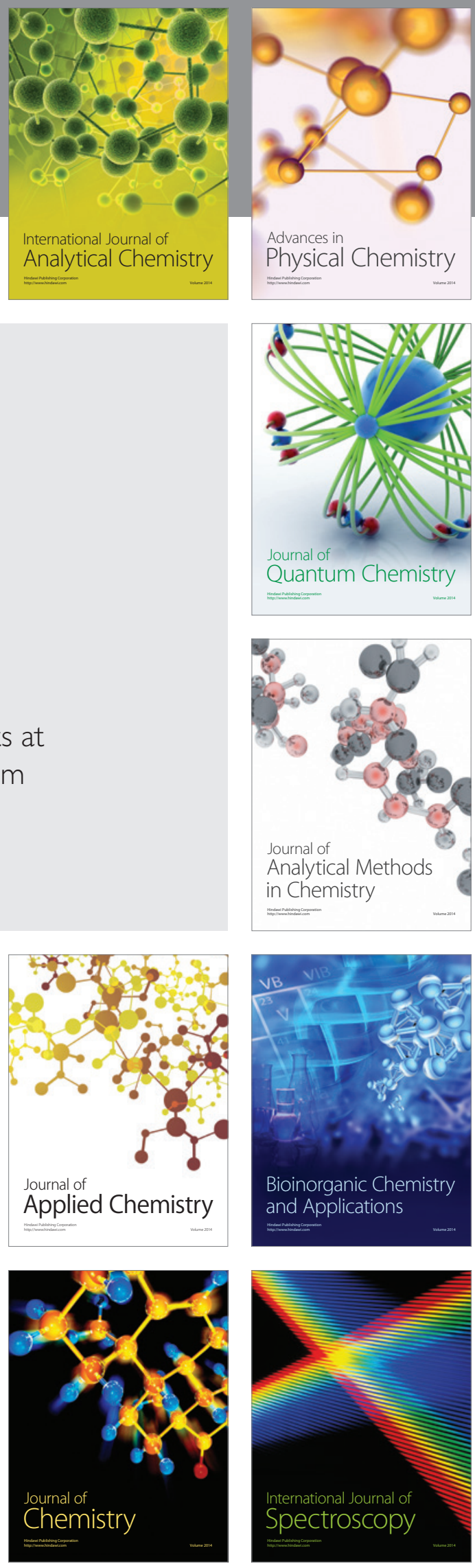